\title{
PERAKENDECILIK SEKTÖRÜNDE TÜKETICILERIN KASIYERSIZ KASALARA ADAPTASYONUNU ETKILEYEN FAKTÖRLERIN INCELENMESI ÜZERINE AMPIRIK BIR ÇALIŞMA
}

\author{
Ümit DOĞRUL $\quad$ Alaiddin KOŞAR
}

Öz

Kasiyersiz kasaları kullanmaya karşı birçok müşteri direnç göstermekte ve geleneksel ödeme yöntemlerini terk etmemektedir. Bu durum yeni teknolojilerin iş süreçlerine adaptasyonunu engellemekte ve yeni teknolojik yatıımların atı kalmasına neden olmaktadır. Bu çalışmanın amacı, tüketicilerin kasiyersiz kasaları kullanımına ilişkin adaptasyonlarını etkileyen faktörleri, teknoloji kabul modeli temel alınarak incelemek ve açıklamaktır. Bu kapsamda, oluşturulan anketler 346 kişiye uygulanmış ve çalışma hipotezleri yapısal eşitlik modeli ile test edilmiştir. Ayrıca aracılık hipotezlerini test etmek amacıyla sobel testi kullanıımıştır. Analiz sonuçlarına göre, kasiyersiz kasanın kullanım kolaylığı algısı, kullanım sonrası algılanan faydası ve kullanım keyfi, kasiyersiz kasa kullanımı sonrası elde edilen tatmini olumlu yönde etkilemektedir. Kasiyersiz kasa kullanımına ilişkin tatmin, tekrar kullanma niyetini olumlu yönde etkilemektedir. Sobel testi analiz sonuçlarına göre ise, tüketicilerin kasiyersiz kasalardan elde ettikleri kullanım kolaylığı, kullanım faydası ve kullanım keyfi algısı ile niyet arasındaki ilişkide, tatmin, aracılık etkisine sahiptir.

Anahtar Kelimeler: Kasiyersiz Kasa, Teknoloji Kabul Modeli, Tüketici Davranışları, Yapısal Eşitlik Modellemesi, Aracilı Etkisi

JEL Sınıflandırması: C12, C83, M31, M39

\section{AN EMPIRICAL STUDY OF FACTORS AFFECTING THE CONSUMERS' ADOPTION OF SELF-SERVICE CHECKOUT SYSTEMS IN RETAILING SECTOR}

\begin{abstract}
Many customers resist the use of self-service checkout systems and do not give up using traditional payment methods. This situation hinders the adaptation to new technologies for business processes and causes new technological investments to remain stagnant. The aim of this study is to examine and explain the factors affecting the adaptation of consumers to the use of self-service checkouts on the basis of the technology acceptance model. Within this scope, questionnaires were devised and applied to 346 people and the study hypotheses were tested using the structural equation model. The Sobel test was also used in order to test the intermediary hypotheses. According to the results of the analysis, the ease-of-use perception of self-service checkouts, the perceived usefulness and enjoyment, positively affect the satisfaction obtained following the use of self-service checkouts. The satisfaction regarding the use of self-service checkouts positively affects the re-use intention. According to the results of the Sobel test, satisfaction in the relationship between the perception of ease of use, perceived usefulness and the enjoyment that consumers obtain from self-service checkout systems and the intention to re-use has an intermediary effect.
\end{abstract}

Keywords: Self-Checkout, Technology Acceptance Model, Consumer Behaviors, Structural Equation Model, Mediation Effect

JEL Classification: C12, C83, M31, M39

${ }^{1}$ Yrd. Doç. Dr., Mersin Üniversitesi, iktisadi ve Idari Bilimler Fakültesi, İşletme Bölümü, udogrul@mersin.edu.tr

2 Arş. Gör., Mersin Üniversitesi, Iktisadi ve Idari bilimler Fakültesi, İşletme Bölümü, alaiddinkosar@mersin.edu.tr 


\section{Giriş}

Günümüzde teknolojinin hızlı bir şekilde gelişmesi gerek iş ortamında gerekse ev ortamında hayatı oldukça kolaylaştırmakta ve hızlandırmaktadır. Hızlı bir şekilde gelişen teknolojiyi ve teknolojik ürünleri kullanma durumu da kişilerin yaşlarına, teknolojiyi kullanma becerilerine, teknolojiden algıladıkları faydalara ve bunun gibi pek çok faktöre göre değiş̧mektedir. Müşterilerin kasiyer görevlisine intiyaç duymaksızın satın almak istedikleri ürünlerin barkodlarını kendilerinin okutmalarına ve daha sonra ödemelerini yaparak kısa sürede alış verişlerini tamamlamalarına olanak sağlayan kasiyersiz kasa da bu teknolojik ürünlerden biridir. Bu teknolojiler, sadece tüketicilere değil aynı zamanda işletmelere de çok sayıda fayda yaratmaktadır. Kasiyersiz kasa teknolojisi sayesinde tüketiciler, yaptıkları alış veriş sonucunda daha kısa sürede ve daha zahmetsiz şekilde mağazadan ayrılırken, işletmeler de mağazadaki trafik akışını kontrol edebilmekte ve hem müşteri tatminini hem de kendi üretkenliklerini arttırabilmektedirler.

Ancak, tüketicilerin bu yeni teknolojilere adaptasyon sağlaması her zaman kolay olmamaktadır. Çoğu tüketici bu tür yeniliklere direnç göstermekte ve bu sebeple yapılan yatırımlar atıl kalmaktadır. Günümüz rekabet ortamında, maliyetleri aşağıya çekmenin önemi göz önüne alındığında bu tür yeni teknolojilerin iş süreçlerine entegre edilmeden önce tüketiciler tarafından kabulünü etkileyen faktörlerin ortaya çıkartılması bu tür yatııımların atıl kalmaması açısından önem arz etmektedir.

Özellikle perakendecilik sektöründe yeni teknolojilerin kullanılması hizmet kalitesini arttırma ve neticesinde müşteri tatminini sağlamak adına gereklidir. Burada önemli olan nokta bu yeni teknolojilerin mağazalara entegre edilmesinden ziyade müşterilerin bu teknolojilere entegre olmasıdır. İşte bu entegrasyonu hızlandıracak faktörlerin belirlenmesi perakendeciler açısından önem arz atmektedir. Konunun önemine rağmen, yabancı yazında kullanım kolaylığı algısı, kullanım faydası algısı ve kullanım keyfi algısının tekrar satın alma niyeti üzerinde etkisinde tatminin aracılık rolünü açıklayan sınırlı sayıda çalışma bulunması, öte yandan Türkiye' de ise tüketicilerin kasiyersiz kasalara adaptasyonunu açıklamaya çalışan böyle bir çalışmaya hiç rastlanmamış olması konunun araştıııması gerekliliğini ortaya koymaktadır. Söz konusu nedenlerden dolayı çalışma pazarlama araştırmacılarına ve uygulayıcılarına ışı tutabilecektir.

Kasiyersiz kasaların atıl kalmaması ve hizmet kalitesinin arttıııması adına bu teknolojinin kullanımını arttıracak faktörlerin belirlenmesi çalışmanın temel problemini oluşturmaktadır. Tespit edilen araştırma problemi ışığında bu çalışmanın amacı ise, tüketicilerin kasiyersiz kasalardan elde ettikleri tatmini etkileyen faktörleri teknoloji kabul modelinden de faydalanarak ortaya koymaktır. Bu temel amaç doğrultusunda çalışmada, algılanan fayda, algılanan kullanım kolaylı̆̆ı ve kullanım keyfi değişkenlerinin tatmine etkisi incelenmektedir. Tatminin ise tekrar kullanma niyetine etkisi belirlenmektedir. Son olarak bu faktörlerin, tekrar kullanma niyeti üzerine etkisinde, tatminin, aracılık rolü incelenmektedir. Bu kapsamda öncelikle çalışmanın kavramsal çerçevesi tartışılmakta, daha sonra araştırma kapsamında araştırma modeline bağlı olarak geliştirilen hipotezler sunularak, araştırmanın yöntemi, verilerin analizi ve bulgularına yer verilmektedir. Çalışmanın son bölümünde ise araştırmaya ilişkin sonuçlar değerlendirilmektedir.

\section{Literatür İncelemesi}

İşgücü maliyetlerindeki artış ve teknolojideki gelişmeler, hizmet işletmelerini, çalışanlardan bağımsız olarak müşterilerin hizmet üretimine olanak sağlayan teknoloji tabanlı hizmetlere yönlendirmiştir. Hizmet üreticileri, teknolojinin bu kullanım şeklini tercih etmektedirler çünkü bu kullanım hizmet faaliyetlerini geliştirmekte, hizmet etkinliğini arttırmakta, müşterilere işlevsel faydalar sağlamakta ve hizmet sunum seçeneklerini genişletmektedir. Bu teknolojik yenilikler, müşteri-firma etkileşiminin önemli bir unsuru olarak işletmelerin uzun dönemli başarısında kilit rol oynayabilmektedir (Lin ve Chang, 2011: 424-425).

Son yıllarda işletmelerin, müşterilerle olan etkileşim şekli değişmiştir. Bu değişim çoğunlukla da hizmet teslim süreci ve hizmet sektörünün doğasını önemli ölçüde etkileyen self-servis teknolojisi 
ile olmuştur. Self-servis teknolojisi kavramı, ilk kez Dabholkar (1994) tarafından ortaya atılmıştır ve tüketicilerin kendi kendilerine kullandıkları, teknoloji tabanlı faydalar ya da faaliyetler olarak tanımlanmıştır. Çok sayıda hizmet işletmesinin, tüketicilerin, hizmetleri kendi kendilerine kullanabilmelerine olanak tanıyan bu teknolojilere uyum sağladıkları görülmektedir (Fernandes ve Pedroso, 2017: 69-70). Özellikle perakendecilik ve bankacılık gibi sektörlerde geleneksel kişilerarası hizmetler yavaş yavaş yerini self-servis teknolojisi ara yüzlerine bırakmaktadır. Mobil hizmetler, interaktif ses yanıt sistemi, internet ve kiosklar şu an firmaların kullandığı self servis teknolojilerine örnek olarak gösterilebilir (Lin ve Chang, 2011: 425).

Perakendecilik sektöründe, mağazalardaki trafik akışını iyileştirme, kasa işlemlerini hızlandırma, müşteri hizmetlerini ve sadakati arttırma gereği, satıcıları yenilikçi çözümler uygulamaya itmiştir. Bu yenilikçi çözümlerden biri de self servis teknolojisi ürünü olan kasiyersiz kasalardır. Kasiyersiz kasa teknolojisi, geleneksel kasalara alternatif oluşturan ve müşterilere mağaza personeli ile etkileşim kurmadan satın alma ve ödeme yapmasına olanak tanıyan teknoloji olarak tanımlanabilir (Sumak, vd., 2014: 453).

Perakendeciler için kasiyersiz kasa gibi self servis teknolojileri aracılığıyla müşterilerin ortak üretime aktif katılım sağlamaları, önem arz etmektedir. Çünkü müşterilerin bu yolla hizmetin verimliliğine önemli katkılar sağlayacağı beklenmektedir (Fernandes ve Pedroso, 2016: 71). Ancak, bireylerin yeni bilgi teknoloji ürünlerini ve sistemlerini kabullenmede ve kullanmada sergiledikleri isteksiz tutumları, kuşkusuz bu sistemlerden beklenen verimin arzu edilen seviyede olmamasına yol açmıştır.

Bu düşünceden yola çıkarak, kullanıcıların bilgi teknoloji ürünlerini neden benimsediklerini veya benimsemediklerini açıklayan psikolojik itici güç ve etkenlerin araştırılmasını temel alan bazı modeller önerilmiştir (Bağıbel vd. , 2010: 333). Özellikle, Gerekçeli Eylem Teorisi, İçerik Temelli Benimseme Modeli, Planlı Davranış Teorisi, Genişletilmiş Teknoloji Kabul Modeli ve Yeniliğin Yayılması Teorisi bu konu hakkındakiönemli teorilerdir. Bilgi sistemlerinin benimsenmesini açıklayabilmek için oluşturulan çok sayıda model içinden Davis tarafından geliştirilen "Teknoloji Kabul Modeli " oldukça güçlü olarak öne çıkmış (Davis vd., 1989) ve araştırmacılar tarafından en çok kullanılan model olmuştur (Kurulgan ve Paşaoğlu, 2013: 55).

Teknoloji Kabul Modeli, kişilerin hem genel hem de teknolojiyi kullanıp kullanamamasına ilişkin davranışlarını açıklayan ve bu davranışları tahmin etmede araştırmacılara yön veren aynı zamanda kullanıcıların yeni teknolojilere adaptasyonlarını ölçmede kullanılabilen bir modeldir (Liao ve Cheung, 2001:302, Hong vd. , 2011:2087). Bu model, kullanıcıların inanç, tutum, niyet ve dolayısıyla kullanım davranışlarını açıklamaya teorik temel oluşturmaktadır (Hong vd. , 2011: 2087).

Bu çalışmada, Davis vd. (1989)' in geliştirdiği teknoloji kabul modeli temel alınarak, modelde yer alan algılanan fayda ve algılanan kullanım kolaylığı değişkenlerinin yanına kullanım keyfi değişkeni de eklenmiştir. Ayrıca kullanıma yönelik tutum yerine kullanım sonrası tatmin değişkeni kullanılmıştır. Çalışmanın modeli Şekil 1' de yer almaktadır. Orijinal teknoloji kabul modeline göre, algılanan fayda ve algılanan kullanım kolaylığı tüketicilerin teknolojilere adaptasyonlarını etkileyen temel iki değişkendir. Bu değişkenler birbirinden ayrı fakat birbirleri ile ilişkili kavramlardır. Algılanan fayda, kullanım deneyiminin sonucuyla ilgilidir, oysa algılanan kullanım kolaylığı, nihai sonuca götüren sonuç olarak görülmektedir (Childers, 2001:513).

Vanketesh (2000:344)'e göre algılanan fayda, teknoloji kabul modeli literatüründe müşterinin yeni teknolojilere adaptasyonunun önemli bir belirleyicisi kabul edilir. Davis (1989:320), algılanan faydayı bir ilişkinin belirli bir sistemi kullanarak iş performansını arttıracağına inancı olarak tanımlamıştır. Özellikle self-servis ödeme sistemlerinin faydacı bir sistem olduğu kabul edilirse, bu sistemin ödemeyi kolaylaştırması, algılanan faydanın önemini çok daha çarpıcı bir şekilde ortaya koymaktadır.

Tüketicilerin yeni teknolojileri benimsemesine etkileyen diğer faktör de kullanım kolaylığı algısıdır. Müşteriler alternatif hizmet sunum seçenekleri arasından karar verirken, hizmet alımı 
esnasında harcadıkları çabanın yani kullanım kolaylığının da önemli olduğunu düşünürler. Kullanım kolaylığı, kişinin bir teknolojiyi basit bulması ve çok çaba harcamadan kullanımını öğrenme derecesidir (Davis vd. , 1989: 987). Tüketiciler yeni teknolojilere adaptasyon süreçlerinde kullanım kolaylığını iki bakımdan değerledirirler. Bunlardan ilki, kullanılan yeni teknolojinin harcanan fiili çabadan tasarruf ettirebilme özelliğinin olmasıdır. Diğeri ise yeni teknolojinin kullanımının sosyal riskinin düşük olmasıdır. Şöyle ki, müşteri teknolojinin kullanımının zor olduğunu düşünürse, bu teknolojiyi kullanmanın sosyal riskinin yüksek olduğunu düşünür. Çünkü bu yeni teknolojiyi kullanırken komik duruma düşmek onun için sosyal risk oluşturacaktır (Dabholkar, 1996:34).

Tüketicilerin yeni teknolojilere adaptasyonunda sadece kullanım kolaylığı ve algılanan fayda gibi faydacı yönlerin değerlendirilmesi, yeni teknolojilerin kabul edilmesini etkileyen soyut ve duygusal faktörlerin dikkate alınmamasına neden olmaktadır. Bu sebeple, son zamanlarda yapılan birçok çalışma, self servis teknolojilerinin kullanımlarının hedonik yönünü de ele almış ve özellikle yeni teknolojilerin kullanılması açısından keyif alma konusu üzerine odaklanılmıştır (Childers, 2001; Dabholker, 1994; Dabholker ve Bagozzi, 2002). Vanketesh (2000:351), algılanan kullanım keyfini, bir sistemin kullanımından elde edilen sonuçlarının ortaya koyduğu performansın dışında, özel bir sistemin kullanımının kendi içinde eğlenceli olarak algılanması olarak tanımlamıştır. Algılanan kullanım kolaylığının bir belirleyicisi olarak, genişletilmiş teknoloji kabul modeline algılanan kullanım keyfi değişkeni de eklenmiştir (Vanketesh, 2000). Yapılan çalışmalarda algılanan kullanım kolaylığı ve fayda, self servis kasaların kullanımının faydacı yönü olarak algılanırken, bazı çalışmalarda ise algılanan kullanım keyfi tatminin ve tekrar kullanma niyetinin bir hedonik yönü olarak ele alınmaktadır (Weijters, vd., 2007).

Literatürdeki çalışmalar göstermektedir ki algılanan kullanım kolaylığı, algılanan kullanım faydası ve algılanan kullanım keyfi, davranışsal niyetleri olumlu yönde etkilemektedir (Kim, vd., 2009; Lanseng ve Andreassen, 2002; Dabholker ve Bagozzi, 2002; Childers vd, 2001; Davis, 1989). Perakendecilik sektöründe kullanılan kasiyersiz kasaların tüketiciler tarafından kabul edilmesini inceleyen bu çalışmada da algılanan kullanım kolaylığı, algılanan kullanım faydası ve algılanan kullanım keyfinin, kullanım sonrası oluşan tatmini olumlu yönde etkilemesi beklenmektedir. Bu doğrultuda $\mathrm{H} 1, \mathrm{H} 2$ ve $\mathrm{H} 3$ hipotezleri geliştirilmiştir.

$\mathbf{H}_{1}$ : Kasiyersiz kasanın kullanım kolaylığı algısı, kasiyersiz kasa kullanımına ilişkin tatmini olumlu yönde etkiler.

$\mathbf{H}_{\mathbf{2}}$ : Kasiyersiz kasa kullanımının algılanan faydası, kasiyersiz kasa kullanımına ilişkin tatmini olumlu yönde etkiler.

$\mathbf{H}_{3}$ : Kasiyersiz kasa kullanımından algılanan keyif, kasiyersiz kasa kullanımına ilişkin tatmini olumlu yönde etkiler.

Son zamanlarda yapılan birçok çalışmada, tatmin tüketicinin tüketim deneyiminden elde ettiği özet bir duygusal tepki olarak ele alınmaktadır (Oliver, 1993:420). Konuyu self servis ödeme teknolojilerinin kullanımı bağlamında ele aldığımızda, aldığı hizmetin kalitesinden memnun olan bir müşterinin farklı alternatifleri değerlendirme olasılığının daha düşük olması beklenir. Ayrıca bu müşteriler mevcut hizmet sağlayıcıları ile daha yakın müşteri ilişkileri geliştireceklerdir (Wang, 2012:132). Bu sebeple, self servis ödeme teknolojilerinin kullanımı neticesinde ortaya çıkan genel tatmin durumunun, ileride hizmeti tekrar kullanma niyetini olumlu etkileyeceği beklenmektedir. $\mathrm{Bu}$ nedenle perakendeciler self servis teknolojilerinin müşteri deneyimlerini olumlu yönde etkileyeceğini ve bunun sonucunda müşteri devamlılığı sağlayabileceklerini öngörmektedirler (Orel ve Kara, 2014.121). Çünkü bir müşterinin, bir hizmetin veya bir organizasyonun genel deneyiminden tatmin olması durumunda, gelecekte de aynı hizmeti veya organizasyonu kullanmak istemesi oldukça olasıdır (Beatson vd., 2007). Hem teknolojik hem de geleneksel hizmetlerin neticesinde ortaya çıkan tatminin, davranışsal niyetlere etkisi çeşitli hizmet araştırmalarında da ortaya konmuştur (Orel ve kara, 2014; Lin; Hsieh, Cronin, 2000). Bu doğrultuda, bu çalışmada da 
tatminin tekrar kullanma niyetini olumlu yönde etkileyeceği göz önünde bulundurularak $\mathrm{H}_{4}$ hipotezi geliştirilmiştir.

$\mathbf{H}_{4}$ : Kasiyersiz kasa kullanımına ilişkin tatmin, kasiyersiz kasayı tekrar kullanma niyetini olumlu yönde etkiler.

Deng (2010), müşterileri tatmin etmenin en önemli faktörlerinden birinin sunulan hizmetler olduğunu ve hizmetlerden elde edilen tatminin ise tekrar kullanma niyetini etkilediğini ileri sürmüştür. Yapılan çalışmalarda self servis kasalardan elde edilen kullanım kolaylığı algısının, elde edilen faydanın ve keyif alma duygusunun, tekrar kullanma niyetini olumlu yönde etkilendiğini ileri süren birçok çalışma mevcuttur ( Dabholker ve Baggozi, 2002; Brown ve Venkatesh, 2005; Oghazi, 2012; Venkatesh, vd. 2012; Venkatesh, 2000; Greenfield ve Rodhe, 2009; Chiu, vd., 2010). Bu çalışmada da self servis ödeme hizmetlerinden elde edilen kullanım kolaylığı algısı, fayda algısı ve kullanım keyfi algısısın tekrar kullanma niyeti üzerine etkisine, tatminin, aracılık ettiği beklenmektedir. Bu doğrultuda $\mathrm{H}_{5}, \mathrm{H}_{6}, \mathrm{H}_{7}$ hipotezleri geliştirilmiştir.

$\mathbf{H}_{5}$ : Algılanan kullanım kolaylığı ve tekrar kullanma niyeti arasındaki ilişkide tatminin aracılık etkisi vardır.

H6: Algılanan kullanım faydası ve tekrar kullanma niyeti arasındaki ilişkide tatminin aracılık etkisi vardır.

$\mathbf{H}_{7}$ : Algılanan kullanım keyfi ve tekrar kullanma niyeti arasındaki ilişkide tatminin aracılık etkisi vardır.

Araştırma problemi ve hipotezleri çerçevesinde geliştirilen araştırma modeli şekil 1' de yer almaktadır.

Şekil 1: Araştırma Modeli

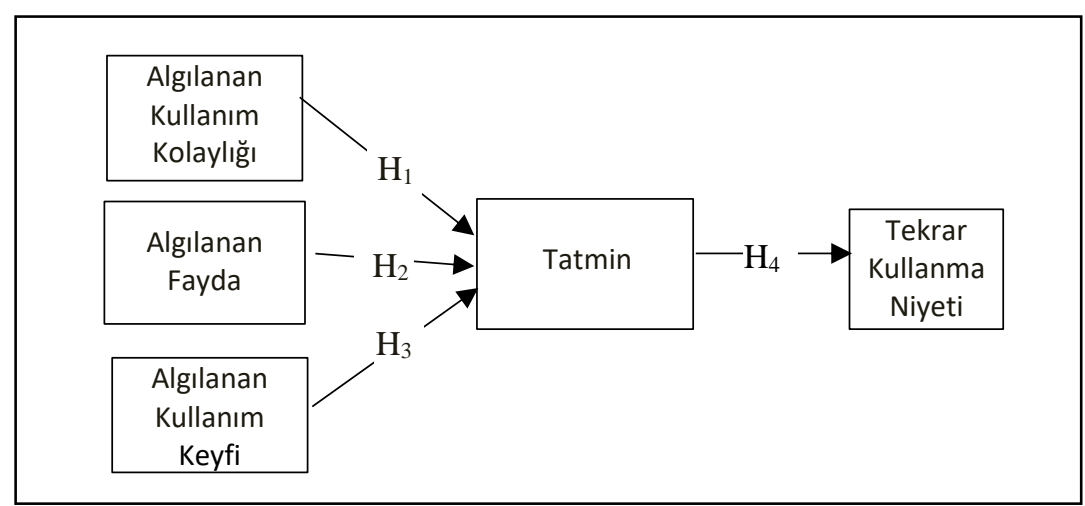

2.Araştırmanın Yöntemi

\subsection{Araştırmanın Türü, evreni ve Örneklemi}

Araştırma bağlamında, çalışmanın evrenini Mersin ilinde perakende mağazalarında kasiyersiz kasayı kullanan tüketiciler oluşturmaktadır. Ancak tüm ana kütleye ulaşılması mümkün olmadığından örnekleme yapılmış ve kolayda örnekleme yöntemi tercih edilmiştir. Anketler, Şubat - Mart 2017 tarihleri arasında toplanmıştır. Örnekleme yönteminin seçimi dışında örnekleme sürecindeki bir diğer önemli konu da, örnek hacminin belirlenmesidir. Ana kütlenin 100.000' in üzerinde olduğu durumda \%95 güven aralığı ve \%5 hata payı ile örneklemin 384 olması gerekmektedir (Yazıcıoğlu ve Erdoğan, 2004). Fakat bu çalışmada veri toplama süreci boyunca 355 kişiye ulaşılabilmiş ve anket uygulanmış fakat 9 anket eksik ve hatalı doldurulduğu için çalışmaya dâhil edilmemiştir. Eksik ve hatalı anketler çıkarıldıktan sonra araştırma hipotezleri 346 geçerli anket üzerinden test edilmiştir. Bu durum çalışmanın bir kısıtı olarak belirlenmiştir. Ayrıca bu çalışmada yapısal eşitlik modeli kullanıldığı için bu yöntemin örnek hacmiyle ilgili gereklilikleri de 
araştırılmıştır. Hoe (2008), 200'ün üzerinde bir örneklemin yapısal eşitlik analizi için yeterli istatistiksel güce sahip bir örnek hacmi olduğunu belirtmiştir. Hair ve diğerleri (2009), yapısal eşitlik yöntemi için örneklem hacmini en az 100-150 olarak önermiştir. Örnek hacminin 400'ün üzerine çıktığında metodun çok hassaslaştığı ve uyum iyiliği değerlerinin zayıfladığını belirlemiştir. Bu değerlendirmeler ışığında yapısal eşitlik modellemesini kullanmak için ulaşılan örnekımen sayısı yeterlidir.

\subsection{Veri Toplama Aracı}

Bu araştırmada veri toplama aracı olarak anket kullanılmıştır. Anket iki bölümden oluşmaktadır. Anketin ilk bölümünde araştırmanın bağımlı ve bağımsız değişkenlerini temsil eden 5 ölçek kullanılmıştır. Anketin ikinci bölümünde ise kişilerin demografik özelliklerini ve kasiyersiz kasa kullanma sıklıklarını belirlemeye yönelik beş soru sorulmuştur. Algılanan kullanım keyfi ve kullanın kolaylığı ölçekleri dört, algılanan fayda ölçeği, üç ifadeden oluşmaktadır. Bu ölçeklere ait ifadeler Childers vd. (2001), Vanketesh ve Bala (2008) ve Dabholker ve Bagozzi (2002)' ın çalışmalarında kullanılan ölçeklerden uyarlanmıştır. Tekrar kullanma niyeti ölçeği, Cronin vd. (2000) çalışmasından alınmış ve iki ifadeden oluşmaktadır. Tatmin ölçeği ise, Dabholkar ve Bagozzi (2002) çalışmasından alınmış ve dört ifadeden oluşmaktadır. Çalışmada, (7) kesinlikle katılıyorum ve (1) kesinlikle katılmıyorum cevaplarını temsil edecek şekilde 7'li likert ölçeği kullanılmıştır.

\section{Ampirik Bulgular}

Örnekleme dahil olan katılımcıların demografik ve sosyo-ekonomik özelliklerine ilşkin frekans ve yüzde değerleri Tablo 1 ' de yer almaktadır.

Tablo 1: Örneklimin Demografik ve Sosyo-Ekonomik Özellikleri

\begin{tabular}{cccccc}
\hline Değişkenler & \multicolumn{2}{c}{$(\mathbf{n}=\mathbf{3 4 6})$} & Değişkenler & \multicolumn{2}{c}{$(\mathbf{n}=\mathbf{3 6 0})$} \\
\hline Cinsiyet & $\mathrm{n}$ & $\%$ & Ĕgitim & $\mathrm{n}$ & $\%$ \\
Kadın & 150 & 43,4 & Okul yazar değil & 5 & 1,4 \\
Erkek & 196 & 56,6 & ilkokul & 7 & 2,0 \\
Yaş & $\mathrm{n}$ & $\%$ & Ortaokul & 130 & 8,7 \\
$16-21$ & 81 & 23,5 & Lise & 120 & 34,7 \\
$22-27$ & 128 & 37,0 & Ön Lisans & 28 & 8,1 \\
$28-33$ & 54 & 15,7 & Lisans & 127 & 36,7 \\
$34-39$ & 35 & 10,1 & Lisansüstü & 29 & 8,4 \\
$40-45$ & 32 & 9,2 & Gelir & $\mathrm{n}$ & $\%$ \\
$46-51$ & 12 & 3,4 & 500 TL' den az. & 38 & 11,0 \\
52 ve üzeri. & 4 & 1,1 & $501-1000$ & 88 & 25,4 \\
& & & $1001-2000$ & 95 & 27,5 \\
& & & $2001-3000$ & 44 & 12,7 \\
& & & $3001-4000$ & 51 & 14,7 \\
& & & 4000 TL üstü. & 30 & 8,7 \\
\hline
\end{tabular}


Tablo 2: Ölçüm Modeline illişkin Doğrulayıcı Faktör Analizi Güvenilirlik ve Geçerlilik Analizi Sonuçları

\begin{tabular}{|c|c|c|c|}
\hline Boyutlar ve Ölçek ífadeleri & $\mathbf{R K}^{*}$ & $\begin{array}{l}\text { Ölç. } \\
\text { Hatası* }\end{array}$ & $\begin{array}{l}\text { CR, VE, } \\
\alpha\end{array}$ \\
\hline \multicolumn{4}{|l|}{ Algılanan Kullanım Keyfi } \\
\hline Kasiyersiz kasa kullanmak heyecan verici bir deneyimdi. & 0,84 & 0,30 & \multirow{4}{*}{$\begin{array}{l}C R=0,89 \\
V E=0,68 \\
\alpha=0,888\end{array}$} \\
\hline Kasiyersiz kasa kullanmak keyifli bir deneyimdi. & 0,88 & 0,23 & \\
\hline $\begin{array}{l}\text { Ürünlerin barkodunu kendim okutmam ve ödeme işlemlerini kendim } \\
\text { yapmam, ödeme sürecimin daha keyifli olmasını sağladı. }\end{array}$ & 0,91 & 0,17 & \\
\hline Kasiyersiz kasayı kullanmak ban sıkıcı geldi. & 0,65 & 0,58 & \\
\hline \multicolumn{4}{|l|}{ Algılanan Kullanım Kolaylığı } \\
\hline Kasiyersiz kasayı kullanmak kolaydı. & 0,87 & 0,25 & $C R=0,90$ \\
\hline Kasiyersiz kasayı kullanmak basit ve anlaşılırdı. & 0,90 & 0,18 & $\mathrm{VE}=0,70$ \\
\hline Kasiyersiz kasayı kullanmak için çok fazla zihinsel çabaya gerek yoktu. & 0,81 & 0,34 & \multirow[t]{2}{*}{$\alpha=0,904$} \\
\hline Kasiyersiz kasada ürünlerin barkodunu okutmak zahmetsizdi. & 0,78 & 0,39 & \\
\hline \multicolumn{3}{|l|}{ Algılanan Fayda } & \multirow{4}{*}{$\begin{array}{l}C R=0,92 \\
V E=0,80 \\
\alpha=0,925\end{array}$} \\
\hline Kasiyersiz kasayı faydalı buldum. & 0,87 & 0,24 & \\
\hline Kasiyersiz kasa bana zaman kazandırdı. & 0,91 & 0,17 & \\
\hline $\begin{array}{l}\text { Kasiyersiz kasa ödeme işlemimi daha hızlı yapmamı sağladı. } \\
\text { Tatmin }\end{array}$ & 0,91 & 0,17 & \\
\hline Kasiyersiz kasa hizmetinden memnun kaldım. & 0,92 & 0,16 & \multirow{4}{*}{$\begin{array}{l}C R=0,87 \\
V E=0,64 \\
\alpha=0,847\end{array}$} \\
\hline Kasiyersiz kasayı kullanmak beni memnun etti. & 0,89 & 0,21 & \\
\hline Kasiyersiz kasanın alış veriş deneyimim üzerinde olumlu etkisi oldu. & 0,83 & 0,32 & \\
\hline $\begin{array}{l}\text { Kasiyersiz kasanın işletmenin sunduğu hizmeti geliştirmede etkisi } \\
\text { olduğunu düşünüyorum. }\end{array}$ & 0,51 & 0,74 & \\
\hline Tekrar Kullanma Niyeti & & & $C R=0,91$ \\
\hline Gelecekte de kasiyersiz kasayı kullanırım. & 0,94 & 0,12 & $V E=0,85$ \\
\hline Aynı markete gittiğimde yine kasiyersiz kasayı kullanırım. & 0,91 & 0,18 & $\alpha=0,919$ \\
\hline
\end{tabular}

$C R=$ Birleşik Güvenirlik VE = Açıklanan Varyans $\alpha=$ Cronbach Alfa

*Standard yük ve hata değerlerinin tamamı 0,01 düzeyinde anlamlıdır.

$C R=\frac{\left(\sum_{i=1}^{n} \lambda_{i}\right)^{2}}{\left(\sum_{i=1}^{n} \lambda_{i}\right)^{2}+\sum_{i=1}^{n} b_{i}} \quad V E=\frac{\sum_{i=1}^{m} \lambda_{i}^{2}}{\sum_{i=1}^{n} \lambda_{i}^{2}+\sum_{i=1}^{n} \theta_{i}}$

Araştırmaya katılanların son altı ay içerisinde kasiyersiz kasa kullanma sıklıklarına ilişkin bulgular incelendiğinde, \%23,1 2 inin sadece bir kez; \%35,82 inin 1-3 kez arası; \%22,8' inin 3-5 kez arası; $\% 10,42$ ünün 5-10 kez arası ve \%7,8' inin ise 10 seferden daha fazla kullandığı belirlenmiştir.

Araştırmanın hipotezlerini test etmeden önce algılanan kullanım keyfi, algılanan kullanım kolaylığı, algılanan fayda, tatmin ve tekrar kullanma niyeti ölçeklerinin geçerlik ve güvenirlikleri sınanmıştır. Ölçeklerin güvenilirliklerini test etmek amacıyla her bir ölçeğin Cronbach Alfa değerleri hesaplanmış ve bu değerler Tablo 2'de verilmiştir. Araştırmada yer alan boyutların ölçeklerine ait alfa değerleri incelendiğinde önerilen 0,70 (Nunnaly, 1978:245) değerinden yüksek olduğu görülmektedir.

Araştırmada kullanılan ölçeklerin yapı geçerliliğini test etmek ve hipotezlerin yapısal eşitlik modeli ile analiz edilmesinden önce, ölçme modelinin iyi uyum değerlerine sahip olup olmadığının belirlemek amacıyla doğrulayıcı faktör analizi uygulanmıştır. Doğrulayıcı faktör analizi neticesinde elde edilen standardize edilmiş faktör yük değerleri, her bir değişkenin içinde bulunduğu faktörü açıklanan varyans düzeyini gösteren $\mathrm{R}^{2}$ değerleri ve standart hatalar Tablo $2^{\prime}$ de verilmiştir. Doğrulayıcı faktör analizi için tüm ilişkilere ait t değerleri 2,58'in üstündedir. T değerlerinin 2,58'in üstünde olması parametre değerlerinin 0,01 düzeyinde anlamlı olmasını ifade etmektedir (Şimşek, 2007: 85). 
Doğrulayıcı faktör analizi kapsamında analiz edilen ölçüm modeli, yapı geçerliliğinin sağlanması açısından da değerlendirilmiştir. Yapı geçerliliğinden söz edebilmek için yakınsama geçerliğinin sağlanması gerekmektedir (Ong ve Van Dulmen, 2007:66). Bir ölçeğin yakınsama geçerliliğini sağlaması için ise birleşik güvenirlik (composite reliability) ve açıklanan ortalama varyansın (average variance extracted) belirli kriterleri sağlaması gerekmektedir (Fornell ve Larcker, 1981: 45). Yakınsama geçerliliğinin sağlanması için; doğrulayıcı faktör analizi kapsamında analiz edilen ölçüm modeline ait boyutların açıklanan ortalama varyans (AVE) değerlerinin 0.50 ve üzerinde ve birleşik güvenilirlik katsayılarının (CR) ise 0.70 değerinin üzerinde olması gerekmektedir (Hair vd, 1995:642). Ölçüm modeline ait boyutların birleşik güvenirlik ve açıklanan varyans değerleri hesaplanarak bu değerlere Tablo 2'de yer verilmiştir. Buna göre, ölçüm modelini oluşturan ölçeklerin birleşik güvenirlik (CR) katsayıları 0.70, açıklanan ortalama varyans değerleri de (VE) 0,50' nin üzerindedir. Modelin bir bütün olarak kabul edilebilirliğini test etmek için uyum iyiliği değerleri incelenmelidir. Doğrulayıcı faktör analizine ilişkin uyum iyiliği değerleri ve uyum iyiliği kriterleri Tablo 3'de verilmiştir. Tablodan görüleceği üzere, çalışmanın örneklem setine ait tüm uyum iyiliği kriterleri, iyi ve kabul edilebilir uyuma sahiptir. Dolayısıyla, doğrulayıcı faktör analizi sonuçları dikkate alındığında, ölçüm modelinde yer alan tüm maddelerin model ile uyumlu olduğu görülmektedir. Bu sonuçlar dikkate alındığında veri setleri ve değişkenler ile yapısal modelin uygulanmasında bir sorun görülmemektedir.

Tablo 3: Doğrulayıcı Faktör Analizi ve Yapısal Eşitlik Modeline iliş̧kin Uyum İndeksleri

\begin{tabular}{|c|c|c|c|c|}
\hline Uyum İndeksi & $\begin{array}{l}\text { Doğrulayıcı } \\
\text { Faktör } \\
\text { Analizi }\end{array}$ & $\begin{array}{l}\text { Yapısal } \\
\text { Eşitlik } \\
\text { Modeli }\end{array}$ & İyi uyum ${ }^{1}$ & Kabul edilebilir uyum ${ }^{1}$ \\
\hline Ki-kare $\left(X^{2}\right)$ & 256,87 & 275,42 & & \\
\hline$x^{2} / d f$ & 2,36 & 2,45 & $0 \leq x^{2} / \mathrm{df} \leq 2$ & $2<\mathrm{X}^{2} / \mathrm{df} \leq 3$ \\
\hline RMSA & 0,063 & 0,065 & $0 \leq \mathrm{RMSA} \leq, 05$ &, $05<\mathrm{RMSA} \leq, 08$ \\
\hline CFI & 0,98 & 0,98 & $, 97 \leq \mathrm{CFI} \leq 1,00$ & ,95< CFI $\leq, 97$ \\
\hline AGFI & 0,89 & 0,88 & $, 90 \leq \mathrm{AGFI} \leq 1,00$ &, $85<\mathrm{AGFI} \leq, 90$ \\
\hline NFI & 0,97 & 0,97 & $, 95 \leq \mathrm{NFI} \leq 1,00$ &, $90<\mathrm{NFI} \leq, 95$ \\
\hline NNFI & 0,98 & 0,98 & $, 97 \leq \mathrm{NNFI} \leq 1,00$ &, $95<\mathrm{NNFI} \leq, 97$ \\
\hline SRMR & 0,046 & 0,049 & $0 \leq \mathrm{SRMR} \leq, 05$ &, $05<\mathrm{SRMR} \leq, 10$ \\
\hline
\end{tabular}

Kaynak: Schermelleh-Engel, K., Moosbrugger, H. \& Müller, H. (2003).

Araştırmanın ilk dört hipotezini test etmek amacıyla yapısal eşitlik modellemesi kullanıımıştır. Araştırma modeline ilişkin uyum iyiliği değerleri dikkate alındığında, tüm uyum iyiliği değerlerinin iyi ve kabul edilebilir değerler içerisinde yer aldığı görülmektedir (Tablo 3).

Yapısal eşitlik modellemesi analiz sonuçlarına göre (Tablo 4), kasiyersiz kasanın kullanım kolaylığı algısının $(\beta=0.26, t=5.72, p<0.01)$, kasiyersiz kasa kullanımından algılanan faydanın $(\beta=0.56, t=11.24, p<0.01)$ ve kasiyersiz kasa kullanımından algılanan kullanım keyfinin $(\beta=0.18$, $\mathrm{t}=4.05, \mathrm{p}<0.01)$, kasiyersiz kasa kullanma tatmini üzerinde pozitif etkisi vardır. Sonuçlar incelendiğinde tatmin üzerinde en fazla etkisi olan değişken algılanan faydadır. Söz konusu üç değişken kasiyersiz kasa kullanımı sonrası elde edilen tatminin \%69'unu açıklamaktadır. Ayrıca, kasiyersiz kasa kullanımına ilişkin tatmin, kasiyersiz kasayı daha sonra da kullanma niyetini olumlu yönde etkilemektedir $(\beta=0.72, t=21.62, p<0.01)$. Analiz sonuçları dikkate alındığında $H_{1}, H_{2}, H_{3}$ ve $\mathrm{H}_{4}$ hipotezleri 0,01'lik anlamlılık düzeyinde kabul edilmiştir.

Araştırmada, self servis ödeme hizmetlerinden elde edilen kullanım kolaylığı algısı, fayda algısı ve kullanım keyfi algısısın tekrar kullanma niyeti üzerine etkisine tatminin aracılık etkisini ölçen $\mathrm{H}_{5}$, $\mathrm{H}_{6}$ ve $\mathrm{H}_{7}$ hipotezlerini test etmek etmek amacıyla Baron ve Kenny (1986) 'in yöntemi dikkate alınmıştır. 
Tablo 4: Hipotez Testi Sonuçları

\begin{tabular}{ccccccc}
\hline Hipotez & Katsayı & $\begin{array}{c}\text { Standart } \\
\text { Hata }\end{array}$ & t değeri & Anlamlılık & $\begin{array}{c}\text { Hipotez } \\
\text { Testi }\end{array}$ & $\mathbf{R}^{\mathbf{2}}$ \\
\hline $\mathbf{H}_{\mathbf{1}}$ & 0,26 & 0,045 & 5,72 & $\mathrm{p}<0,01$ & Kabul & \\
$\mathbf{H}_{\mathbf{2}}$ & 0,56 & 0,035 & 11,24 & $\mathrm{p}<0,01$ & Kabul & $\mathbf{0 , 6 9}$ \\
$\mathbf{H}_{\mathbf{3}}$ & 0,18 & 0,05 & 4,05 & $\mathrm{p}<0,01$ & Kabul & \\
$\mathbf{H}_{\mathbf{4}}$ & 0,72 & 0,048 & 14,98 & $\mathrm{p}<0,01$ & Kabul & $\mathbf{0 , 5 2}$ \\
\hline
\end{tabular}

Baron ve Kenny'in yönteminde, aracılık ilişkisi bazı koşullların gerçekleşme durumu ile tespit edilmektedir. Bu koşullara göre, yordayıcı ve aracı değişken arasındaki (a); aracı değişken ve yordanan değişken arasındaki (b) ve son olarak yordayıcı ve yordanan değişken arasındaki (c) ilişkiler anlamlı olmalıdır. Ayrıca, aracı değişken ile yordayıcı değişken birlikte modele dâhil olduğunda yordayıcı ve yordanan arasındaki ilişkinin anlamsız duruma gelmesi veya etkisinin düşmesi gerekmektedir. Söz konusu durumda ilişkinin derecesinde düşme meydana gelmesi "kısmi aracılığın” göstergesi olurken; ilişkinin istatistiksel olarak anlamlı olmaması, "tam aracılığın” bir göstergesi olmaktadır (Şimşek, 2007, 23).

Aracılık hipotezlerini $\left(\mathrm{H}_{5}, \mathrm{H}_{6}, \mathrm{H}_{7}\right)$ test etmek amacıyla SPSS paket programı üzerinde çalışan PROCESS olarak adlandırılan bir makro kullanılmıştır. Aracılık etkisin anlamlılığını test etmek amacıyla ise sobel testinden yararlanılmıştır. Sobel testi sonucunda elde edilen Z skor katsayısı 1,96'dan büyük olması durumunda söz konusu aracı etkinin varlığından ve istatistiksel olarak anlamlılı̆̆ından söz edilebilir (Frazier, vd., 2004:128).

Şekil 2: Algılanan Kullanım Kolaylığı ve Tekrar Kullanma Niyeti Arasındaki illişkide Tatminin Aracılık Etkisi

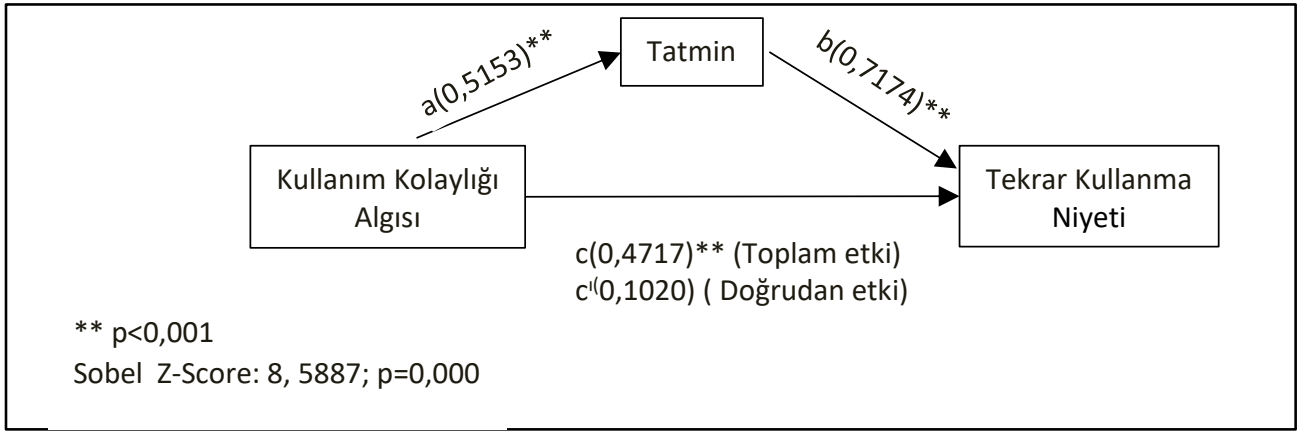

$\mathrm{H}_{5}$ hipotezini test etmek amacıyla, Şekil 2'deki analiz sonuçları değerlendirildiğinde, kullanım kolaylığı algısı (yordayıcı) ve tatmin (aracı) arasında ( $a=0,51553, p<0,001)$; tatmin (aracı) ile tekrar kullanma niyeti (yordanan) arasında ( $b=0,71574, p<0,001)$ ve kullanım kolaylığı algısı (yordayıcı) ile tekrar kullanma niyeti (yordanan) arasında $(c=0,4717, p<0,001)$ istatistiksel olarak anlamlı ilişkiler olduğu görülmektedir. Söz konusu durumda, aracı etkiden söz edebilmek için olması gereken şartların sağlandığı görülmektedir. Fakat aracı etkinin olduğunu söyleyebilmek için aracı ve bağımsız değişkenler modele beraber girdiklerinde yordayıcı ve yordanan arasındaki ilişkinin var olup olmadığına veya ilişkinin derecesinin azalıp azalmadığına bakılmalıdır. Şekil 2 dikkate alındığında, kullanım kolaylığı algısı (yordayıcı) ile tatmin(aracı) birlikte modele dahil olduğunda yordayıcı ve yordanan arasındaki ilişkinin istatistiksel olarak anlamsız duruma $\left(c^{1}=0,1020, p>0,10\right)$ geldiği görülmektedir. Bu sonuca göre tam aracılık etkisinin varlığından söz edilebilmektedir. 
Tablo 5: Algılanan Kullanım Kolaylı̆̆ı, Tatmin ve Tekrar Kullanma Niyeti Arasındaki Etkiler

\begin{tabular}{lllll}
\hline \multirow{2}{*}{ Etkiler } & Nokta Tahmin & \multicolumn{2}{l}{ Katsayılar Çarpanı } \\
\cline { 3 - 5 } & $\mathbf{z}$ & $\boldsymbol{P}$ & Aracı Etki türü \\
\hline Dolaylı etki & $0,3697^{* *}$ & 8,5887 & $.000^{* *}$ & Tam Aracılık \\
Toplam etki & $0,4717^{* *}$ & & & \\
Doğrudan etki & 0,1020 & & & \\
\hline$* * \mathrm{p}<0,001$ & & & &
\end{tabular}

Kullanım kolaylığı algısı ile tatmin birlikte modele dâhil olduğunda, yordayıcı ve yordanan arasındaki ilişkinin istatistiksel olarak anlamsız duruma gelmesi aracı etkiden söz etmek için tek başına yeterli değildir. Söz konusu aracı etkinin istatistiksel olarak anlamlı olup olmadığını tespit etmek amacıyla Sobel testi yapılmıştır. Sobel testine göre, Z skor 8,5887 ve anlamlılık düzeyi $p<0,001^{\prime}$ dir. Sobel testi sonucuna göre, kullanım kolaylığı algısının tatmin aracılı̆̆ıla, tekrar kullanma niyeti üzerindeki dolaylı etkisi istatistiksel açıdan da anlamlıdır. Bu duruma göre $\mathrm{H}_{5}$ hipotezi kabul edilmiştir. Ayrıca, aracı etkinin gücünü ortaya koymak amacıyla dolaylı, doğrudan ve toplam etkilerin de dikkate alınması gerekir. Söz konusu etkiler Tablo 5'te yer almaktadır. Toplam etki $(0,4717)$ ile doğrudan etki $(0,1020)$ arasındaki fark dolaylı etkiyi $(0,3697)$ vermektedir. Söz konusu dolaylı etki aracılık etkisinin de gücünü göstermektedir.

\section{Şekil 3: Algılanan Kullanım Faydası ve Tekrar Kullanma Niyeti Arasındaki ílişkide Tatminin Aracilık Etkisi}

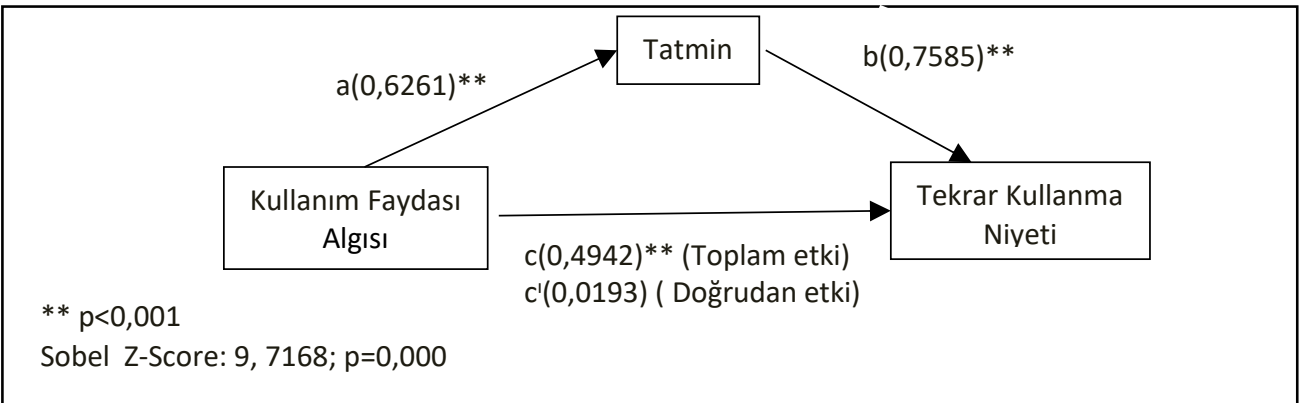

$\mathrm{H}_{6}$ hipotezini test etmek amacıyla Şekil 3'deki analiz sonuçları değerlendirildiğinde, kullanım faydası ve tatmin arasında $(a=0,6261, p<0,001)$; tatmin ile tekrar kullanma niyeti arasında( $b=0,7585, p<0,001)$ ve kullanım faydası algısı ile tekrar kullanma niyeti arasında ( $c=0,4942, p<0,001)$ istatistiksel olarak anlamlı ilişkiler olduğu görülmektedir. Kullanım faydası algısı ile tatmin birlikte modele dâhil olduğunda yordayıcı ve yordanan arasındaki ilişkinin istatistiksel olarak anlamsız duruma $\left(c^{1}=0,0193, p>0,10\right)$ geldiği görülmektedir. Bu sonuca göre tam aracılık etkisinin varlığından söz edilebilmektedir.

Tablo 6: Algılanan Kullanım Faydası, tatmin ve Tekrar Kullanma Niyeti Arasındaki Etkiler

\begin{tabular}{lllll}
\hline & & \multicolumn{2}{l}{ Katsayılar Çarpanı } & \\
Etkiler & Nokta Tahmin & $\mathbf{z}$ & $\boldsymbol{P}$ & Aracı Etki türü \\
\hline Dolaylı etki & $0,4749^{*}$ & 9,7168 & $.000^{* *}$ & Tam Aracılık \\
Toplam etki & $0,4942^{* *}$ & & & \\
Doğrudan etki & 0,0193 & & & \\
\hline
\end{tabular}

** $p<0,001$

Sobel testi sonucuna göre, Z skor 9,7168 ve anlamlılık düzeyi $p<0,001$ 'dir. Sobel testi sonucuna göre, kullanım faydası algısının tatmin aracılığıyla, tekrar kullanma niyeti üzerindeki dolaylı etkisi istatistiksel açıdan da anlamlıdır. Bu duruma göre $\mathrm{H}_{6}$ hipotezi kabul edilmiştir. Tablo 6 
incelendiğinde toplam etkinin “0,4749”, doğrudan etki “0,0193” ve dolaylı etkinin “0,4749” olduğu görülmektedir. Söz konusu dolaylı etkinin derecesi aracılık etkisinin gücünü göstermektedir.

Şekil 4: Algılanan Kullanım Keyfi ve Tekrar Kullanma Niyeti Arasındaki ilişkide Tatminin Aracılık Etkisi

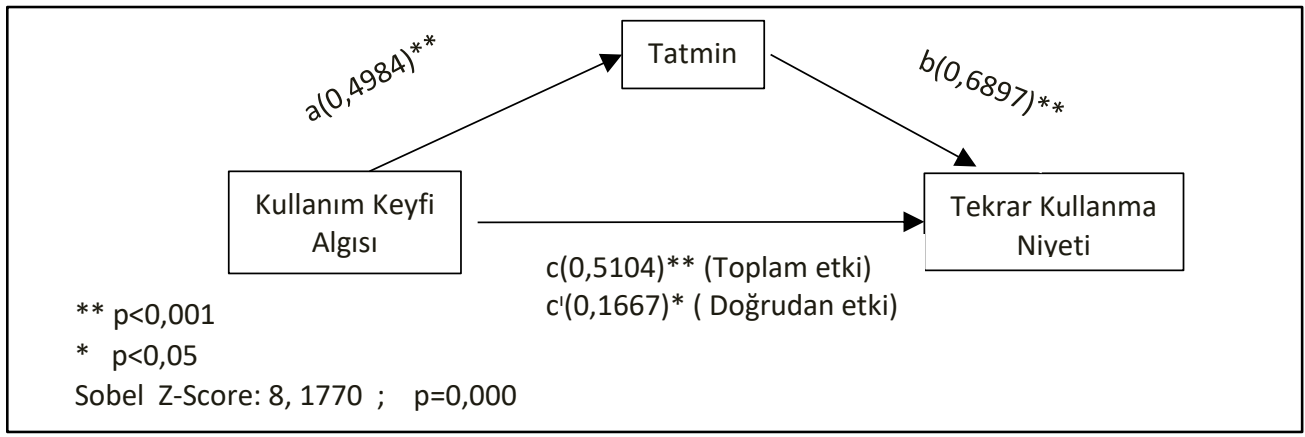

H7 hipotezini test etmek amacıyla Şekil 4'deki analiz sonuçları değerlendirildiğinde, kullanım keyfi ve tatmin arasında $(a=0,4984, p<0,001)$; tatmin ile tekrar kullanma niyeti arasında( $b=0,6897$, $p<0,001)$ ve kullanım keyfi algısı ile tekrar kullanma niyeti arasında $(c=0,5104, p<0,001)$ istatistiksel olarak anlamlı ilişkiler olduğu görülmektedir. Kullanım keyfi algısı ile tatmin birlikte modele dâhil olduğunda yordayıcı ve yordanan arasındaki ilişkinin anlamlı olduğu fakat gücünün azaldığı (c1 $=0,0193, p>0,10)$ görülmektedir. Bu sonuca göre kısmi aracılık etkisinin varlığından söz edilebilmektedir.

Tablo 7: Algılanan Kullanım Keyfi, Tatmin ve Tekrar Kullanma Niyeti Modeli Arasındaki Etkiler

\begin{tabular}{lllll}
\hline & & \multicolumn{2}{l}{ Katsayılar Çarpanı } & \\
Etkiler & Nokta Tahmin & $\mathbf{z}$ & $\boldsymbol{P}$ & Aracı Etki türü \\
\hline Dolaylı etki & $0,3437^{* *}$ & 8,1770 & $.000^{* *}$ & Kısmi Aracılık \\
Toplam etki & $0,5104^{* *}$ & & & \\
Doğrudan etki & 0,1667 & & & \\
\hline
\end{tabular}

$* * \mathrm{p}<0,001$

Sobel testi sonucuna göre, $Z$ skor 8,1770 ve anlamlılık düzeyi $p<0,001^{\prime}$ dir. Sobel testi sonucuna göre, kullanım keyfi algısının tatmin aracılığıyla, tekrar kullanma niyeti üzerindeki dolaylı etkisi istatistiksel açıdan da anlamlıdır. Bu duruma göre $\mathrm{H}_{7}$ hipotezi kabul edilmiştir. Tablo 7 incelendiğinde toplam etkinin " 0,5104 ", doğrudan etki " 0,1667 " ve dolaylı etkinin " 0,3437 " olduğu görülmektedir.

\section{Sonuç}

Günümüz rekabet ortamında yeni teknolojleri iş süreçlerine entegre etme işletmelere önemli rekabet avantajları kazandırmaktadır. Perakendecilik sektörü de bu teknolojik gelişmelerden etkilenmektedir. Müşterilerin, kasiyer görevlisine ihtiyaç duymadan alış verişlerini tamamlamalarına olanak sağlayan kasiyersiz kasalar da bu teknolojik ürünlerden biridir. Ancak herkes tarafından teknolojinin kabulünün çok hızlı olmaması, geliştirilen veya yatırım yapılan yeni teknolojilerin kimi zaman atıl kalmasına ve işletmelere önemli maliyetler yüklemesine yol açabilmektedir. Bu çalışmanın da amacı son zamanlarda perakendecilik sektöründe kullanımı gittikçe artan kasiyersiz kasaların tüketicilerin kullanım sonrası elde ettikleri tatminini etkileyen faktörleri ortaya koymaktır. Ayrıca çalışmada bu faktörlerin, tekrar kullanma niyeti üzerine etkisinde tatminin aracılık rolü de incelenmiştir.

Araştırmaya ilişkin bulgular dikkate alındı̆̆ında, kasiyersiz kasanın kullanım kolaylı̆̆ı, kullanım sonrası algılanan faydası ve kullanım keyfi ile kasiyersiz kasa kullanımı sonrası elde edilen tatmin arasında pozitif ve istatistiksel olarak anlamlı bir ilişki tespit edilmiştir. Bu sonuçlar, literatürde daha 
önce yapılan çalışmaları destekler niteliktedir (Kim, Chun ve Song, 2009; Lanseng ve Andreassen, 2002; Dabholker ve Bagozzi, 2002; Childers vd, 2001; Davis, 1989; Venkatesh, 1999). Araştırma sonuçları göstermektedir ki yeni bir teknolojinin insanlar tarafından kabul edilmesi için gerekli olan temel şart fayda sağlamasıdır. Fakat yeniliğin insanlara fayda sağlaması tek başına yeterli değildir. Faydanın kullanım kolaylığı ve kullanımın keyifli olması ile desteklenmesi de gerekmektedir. Ayrıca analiz sonuçlarına göre kasiyersiz kasa kullanımına ilişkin tatmin tekrar kullanma niyetini olumlu yönde etkilemektedir. Benzer şekkilde, Dabholker ve Baggozi (2002), Brown ve Venkatesh (2005), Venkatesh (2000)' de çalışmalarında yeni bir teknolojiyi kullanımdan elde edilen tatminin tekrar kullanma niyetini olumlu yönde etkilediğini ileri sürmüşlerdir.

Çalışmada tatminin, kullanım kolaylığı algısı, kullanım faydası ve kullanım keyfi algısı değişkenleri ile tekrar kullanma niyeti arasındaki ilişkide aracılık etkiside incelenmiştir. Analiz sonuçlarına göre, tatmin değişkeninin kullanım kolaylığı algısı ile tekrar kullanma niyeti arasında ve kullanım faydası algısı ile tekrar kullanma niyeti arasında tam aracılık etkisine sahip olduğu belirlenmiştir. Diğer taraftan analiz sonuçları göstermektedir ki tatmin kullanım keyfi algısı ile tekrar kullanma niyeti arasında kısmi aracılık etkisine sahiptir. Aracılık analizi sonuçlarına göre tüketicilerin self servis kasaları tekrar kullanmaları bakımından self servis kasanın kullanım kolaylığının, kullanım keyfinin ve faydasının etkisi, elde edilen tatminle birlikte daha da artmaktadır. Bu sonuç göstermeketedir ki yatırım yapılan yeni bir teknolojiinin atıl kalmaması için mutlaka kullanıcıların beklentileri karşılanmalı ve hatta aşılmalıdır. Müşteri tatmin olmadı takdirde kasiyersiz kasayı tekrar kullanmak istememektedir.

Kasiyersiz kasaların zamanla daha çok kullanılacağı ve işletmelerin hizmet kalitelerine katkıda bulunacağı dikkate alındığında bu teknolojinin tüketiciler tarafından kabul edilmesinde etkili olan faktörlerin belirlenmesi pazarlama uygulamacıları açısından önem arz etmektedir. Çünkü teknolojiyi yeni iş süreçlerine entegre etmek, rekabet avantajı elde etmek için tek başına yeterli değildir. Bu entegrasyonun tüketiciler tarafından benimsenmesiyle birlikte yeni teknolojileri kullanmak anlam kazanacaktır.

Sonuç olarak, işletme yöneticileri, kasiyersiz kasalar gibi hizmet kalitesini arttırabilecek ve müşteriye değer kazandırabilecek yeni uygulamaları kurarken bu uygulamaların tüketicilere fayda sunup sunmayacağına, kullanım kolaylığı sunup sunmayacağına ve tüketici için keyifli bir şekilde kullanılabilir olup olmadığına dikkat etmelidirler.

\section{Kaynakça}

Bağlıbel, M., Samancıoğlu, M. ve Summak, M. S. (2010). Okul Yöneticileri Tarafından E-Okul Uygulamasının Genişletilmiş Teknoloji Kabul Modeline Göre Değerlendirilmesi. Mustafa Kemal Üniversitesi Sosyal Bilimler Enstitüsü Dergisi, 13(7), 331-348.

Baron, R. M. ve Kenny, D. A. (1986). The Moderator-Mediator Variable Distinction in Social Psychological Research: Conceptual, Strategic and Statistical Considerations. Journal of Personality and social Psychology, 51, 1173-1182.

Beatson, A., Lee, N. ve Coote, L. (2007) Self-Service Technology and the Service Encounter. The Service Endustry Journal, 27(1),75-89.

Brown, S. A. ve Venkatesh, V. (2005). Model of Adoption of Technology in the Household: A Baseline Model Test and Extension Incorporating Household Life Cycle. MIS Quarterly, 29(4), 399-426.

Childers, T. L., Christopher L. C., Joann, P. ve Stephen, C. (2001). Hedonic and Utilitarian Motivations for Online Retail Shopping Behavior. Journal of Retailing, 77, 511-535.

Chiu, Y. T., Fang, S. C. ve Tseng, C. C. (2010). Early Versus Potential Adopters: Exploring the Antecedents of Use Intention in the Context of Retail Service Innovations. International Journal of Retail \& Distribution Management, 38(6), 443-459. 
Cronin, J. J., Brady, M. K. ve Hult, G. T. M. (2000). Assessing the Effects of Quality, Value, and Customer Satisfaction on Consumer Behavioral Intentions in Service Encounters. Journal of Retailing, 76(2), 193-218.

Dabholkar, P. A. (1994). Technology-Based Service Delivery: A Classification Scheme for Developing Marketing Strategies. Advances in services marketing and management, 3(1), 241-271.

Dabholkar, P. A. (1996). Consumer Evaluations of New Technology Based Self-Service Options: An Investigation of Alternative Models of Service Quality. International Journal of Research in Marketing, 13, 29-51.

Dabholkar, P. A. ve Bagozzi, R. P. (2002). An Attitudinal Model of Technology-Based Self-Service: Moderating Effects of Consumer Traits and Situational Factors. Journal of the Academy of Marketing Science, 30(3), 184-201.

Davis, F. D. (1989). Perceived Usefulness, Perceived Ease of Use, and User Acceptance of Information Technology. MIS Quarterly, 13(3), 319-340.

Davis, F. D., Bagozzi, R. P. ve Warshaw, P. R. (1989). User Acceptance of Computer Technology: A Comparison of Two Theoretical Models. Management Science, 35(8), 982-1003.

Deng, Z., Lu, Y., Wei, K. K. ve Zhang, J. (2010). Understanding Customer Satisfaction and Loyalty: an Empirical Study of Mobile Instant Messages in China. International Journal of Information Management, 30(4), 289-300.

DeVellis, R. F. (1991). Scale Development: Theory and Applications. Sage Publications, U.S.A..

Fernandes, T. ve Pedroso, R. (2017). The Effect of Self-Checkout Quality on Customer Satisfaction and Repatronage in a Retail Context. Service Business, 11(1), 69-92.

Frazier, P. A., Tix, A. P. ve Baron, K. E. (2004). Testing Moderator and Mediator Effects in Counseling Psychology Research. Journal of Counseling Psychology, 51(1), 115-134.

Greenfield, G. ve Rohde, F. (2009). Technology Acceptance: Not All Organizations or Workers May Be the Same. International Journal of Accounting Information Systems, 10(4), 263-272.

Hair, J. F., Anderson, R. E., Tatham, R. L. ve Black, W. C. (1995). Multivariate Data Analysis with Readings (4th Edition). New Jersey: Prentice Hall.

Hair, J. F., Black, W. C., Babin, B. J., ve Anderson, R. E. (2009). Multivariate Data Analysis (Global Ed.). Pearson Education.

Hoe, S.L. (2008). Issues and Procedures in Adopting Structural Equation Modeling Technique. Journal of Applied Quantitative Methods, 3(1), 76-83.

Hong, J. C., Hwang, M. Y., Hsu, H. F., Wong, W.T. ve Chen, M .Y. (2011). Applying the Technology Acceptance Model in a Study of the Factors Affecting Usage of the Taiwan Digital Archives System. Computers \& Education, 57, 2086-2094.

Kim, Y. J., Chun, J. U. ve Song, J. (2009). Investigating the Role of Attitude in Technology Acceptance From an Attitude Strength Perspective. International Journal of Information Management, 29, 67-77.

Kurulgan, M. ve Paşaoğlu, D. (2013). Bilgi Profesyonellerinin Bilgi Teknolojisi Kullanma Eğilimlerinin Belirlenmesi Üzerine Üniversite Kütüphanelerinde Yapılan Karşılaştırmalı Bir Araştırma. Türk Kütüphaneciliği, 27(1), 52-78.

Lanseng, E. J. ve Andreassen, T. W. (2007). Electronic Healthcare: A Study of People's Readiness and Attitude Toward Performing Self-Diagnosis. International Journal of Service Industry Management, 18(4), 394-417. 
Liao, Z. ve Cheung, M. T. (2001). Internet-Based E-Shopping and Consumer Attitudes an Empirical Study. Information \& Management, 38(5), 299-306.

Lin, C. ve Hsieh, P. (2011). Assessing the Self-Service Technologies Encounters: Development and Validation of SSTQUAL Scale. Journal of Retailing, 87(2), 194-206.

Lin, J. S. C. ve Chang, H. C. (2011). The Role of Technology Readiness in Self-Service Technology Acceptance. Managing Service Quality An International Journal, 21(4), 424-444.

Nunnally, J. C. (1978). Psychometric Theory. New York: Mc Graw-Hill.

Oghazi, P., Mostaghel, R., Hultman, M. ve Parida, V. (2012). Antecedents of Technology-Based SelfService Acceptance: A Proposed Model. Services Marketing Quarterly, 33(3), 195-210.

Oliver, R. L. (1993). Cognitive, Affective, and Attribute Bases of the Satisfaction. Journal of Consumer Research, 20(3), 418-430.

Ong, A. D. ve Van Dulmen, M. H. N. (2007). Handbook of Methods in Possitive Psychology. Oxford University Press.

Orel, F. ve Kara, A. (2014). Supermarket Self-Checkout Service Quality, Customer Satisfaction, and Loyalty: Empirical Evidence From an Emerging Market. Journal of Retailing and Consumer Services, 21(4), 118-129.

Sumak, B., Pusnik, M. ve Hericko, M. (2014). An Empirical Study of Factors Affecting the Adoption of Self-Service Checkout Terminals in Slovenia. 37. International Convention on Information and Communication Technology, Electronics and Microelectronics (MIPRO), Opatija, Croatia.

Schermelleh-Engel, K., Moosbrugger, H. ve Müller, H. (2003). Evaluating the Fit of Structural Equation Models: Tests of Significance and Descriptive Goodness-of-Fit Measures. Methods of Psychological Research, 8(2), 23-74.

Şimşek, Ö. F. (2007). Yapısal Eşitlik Modellemesine Giriş. Ankara: Ekinoks Yayınları.

Venkatesh, V. (2000). Determinants of Perceived Ease of Use: Integrating Control, Intrinsic Motivation, and Emotion in to the Technology Acceptance Model. Information Systems Research, 11(4), 342-365.

Venkatesh, V. ve Bala, H. (2008). Technology Acceptance Model 3 and a Research Agenda on Interventions. Decision Sciences, 39(2), 273-315.

Venkatesh, V., Tong, J. Y. ve Xu, X. (2012). Consumer Acceptance and Use of Information Technology: Extending the Unified Theory of Acceptance and Use of Technology. MIS Quarterly, 36(1), 157-178.

Yazıcıoğlu, Y. ve Erdoğan, S. (2004). Spss Uygulamalı Bilimsel Araştırma Yöntemleri. Ankara: Detay Yayıncılık.

Wang, M. ve Chih-Hung. (2012). Determinants and Consequences of Consumer Satisfaction with Self-Service Technology in a Retail Setting. Managing Service Quality: An International Journal, 22(2), 128-144.

Weijters, B., Rangarajan, D., Falk, T. ve Schillewaert, N. (2007). Determinants and Outcomes of Customers' Use of Self-Service Technology in A Retail Setting. Journal of Service Research, 10(1), 3-21. 
AN EMPIRICAL STUDY OF FACTORS AFFECTING THE CONSUMERS' ADOPTION OF SELF-SERVICE CHECKOUT SYSTEMS IN RETAILING SECTOR

\section{Extended Abstract}

Aim: The integration of new technologies to business processes in the current competitive environment helps businesses to gain significant competitive advantages. The retail sector is also affected by these technological advancements. Self-service checkout systems, which allow consumers to complete their shopping without any need for cashiers, are also one of these technological products. However, the overall acceptance of this technology by consumers may not be very rapid. Many customers resist the use of Self-service checkout systems and do not give up using traditional payment methods. This situation hinders the adaptation to new technologies for business processes and causes new technological investments to remain stagnant. The aim of this study is to examine and explain the factors affecting the adaptation of consumers to the use of self-service checkout systems on the basis of the technology acceptance model.

Method(s): The research sample comprised consumers who use self-service checkout systems in retail shops in Mersin Province. The data used in the research was collected with questionnaires and the convenience sampling technique using the non-probability sampling method. The research hypotheses were tested taking into account the 346 valid questionnaires. First of all, confirmatory factor analysis was applied in order to test the construct validity of the scales used in this research and to determine whether or not the measurement model had good compatibility values, before the hypotheses were analyzed using the structural equation model. Then structural equation modeling was used to test the first four research hypotheses. Lastly, the PROCESS macro for SPSS, developed by Hayes, was used in order to test the hypotheses of intermediary relationship. The Sobel Test was also used to identify the significance of intermediary effect.

Findings: When the goodness of fit scores in structural equation model were examined, all the scores could be seen to have good compatibility reference values $(x 2 / d f=2.45, R M S A=0.065$, $\mathrm{CFI}=0.98, \mathrm{GFI}=0.91, \mathrm{NFI}=0.97, \mathrm{AGFI}=0.88, \mathrm{NNFI}=0.99$ ). The research model tested according to this situation was an acceptable and valid model.

According to the results of the structural equation modeling, it was determined that the perception for ease-of-use of self-service checkout systems $(\beta=0.26, t=5.72, p<0.01)$, the perceived usefulness from the use of self-service checkout systems $(\beta=0.56, t=11.24, p<0.01)$ and perceived enjoyment from the use of self-service checkout systems $(\beta=0.18, t=4.05, p<0.01)$ had positive effects on satisfaction in the use of self-service checkout systems. When the results were examined, the variable that had the greatest effect on satisfaction could be seen as the perceived benefit. These three variables explain $69 \%$ of the satisfaction obtained following the use of self-service checkout systems. Moreover, satisfaction in the use of self-service checkout systems positively affected the intention to re-use self-service checkout systems $(\beta=0.72, t=21.62, p<0.01)$.

The Sobel test was used in order to measure the intermediary effect of satisfaction. According to the results of the Sobel test, the satisfaction in the relationship between the ease-of-use perception, which consumers gained from self-service checkout systems and the intention, had a full mediation effect. The satisfaction in the relationship between the benefit perceived usefullness that consumers gained from self-service checkout systems and the intention to re-use had a full mediation effect. The satisfaction in the relationship between the perception of enjoyment that consumers gained from self-service checkout systems and the intention to re-use had a partially mediation effect.

Conclusion: When it is taken into account that self-service checkout systems will be used ever more over time and will contribute to the service quality of businesses, the identification of the factors that have an effect on the acceptance of this technology by consumers is important for marketing pragmatists. Since the integration of technology into new business processes is, on its own, not 
sufficient to gain competitive advantage, the use of new technologies will be significant with the adoption of this integration by consumers.

The research results show that the fundamental condition required for the acceptance of a new technology by society is the benefit it offers. However, the benefit offered by new technology alone is not sufficient. The benefit needs to be supported by ease-of-use and enjoyment. When all these results are taken into account, while installing these new technologies, such as self-service checkout systems, business managers should consider whether or not new applications can benefit consumers or be easily and enjoyably used, which may improve the service quality and add value for customers. 